\title{
Excisional Arthroplasty for Isolated Scaphotrapeziotrapezoidal Arthritis with the Use of Palmaris Longus Tendon
}

\author{
Konstantinos RAPTIS ${ }^{a}$, ${ }^{\text {, Christos KOUTSERIMPAS }}$, Aikaterini BAVELOU ${ }^{a}$, \\ Emmanouil FANDRIDISa, Sarantis SPYRIDONOS ${ }^{a}$ \\ aHand-Upper Limb-Microsurgery Department, General Hospital KAT, Athens, Greece \\ bDepartment of Orthopaedics and Traumatology, \\ "251" Hellenic Air Force General Hospital of Athens, Greece
}

\begin{abstract}
Background: Introduction: Isolated scaphotrapeziotrapezoidal (STT) joint osteoarthritis (OA) is a relatively common condition. Scaphotrapeziotrapezoidal arthrodesis is the traditional treatment, while excisional arthroplasty with the use of flexor carpi radialis (FCR) or polycarbon implants represents a promising alternative surgical management. The present study aims to assess a novel alternative technique of excisional arthroplasty with the use of palmaris longus $(P L)$ tendon as interposition material.

Materials: The present research is a retrospective observational study. Patients suffering from symptomatic isolated STT OA, without midcarpal instability and treated with excisional arthroplasty with the use of PL tendon as interposition material, were evaluated. Five patients (two males and three females) with mean age of 63.8 years [standard deviation $(S D)=16.9$ ] were included. The mean follow up was 56.4 months ( $S D=9.8$ ). In order to quantify the clinical results, we used the preoperative and postoperative visual analogue scale (VAS) score at rest and during activity, abbreviated Disabilities of the Arm, Shoulder and Hand (QuickDASH) score and postoperative ROM.

Results: The postoperative VAS score at rest and during activity showed a decrease of $86.2 \%$ and $62.5 \%$, respectively, when compared to the preoperative one. Regarding postoperative ROM at final follow-up, patients had a mean wrist flexion $71^{\circ}$ compared to $78^{\circ}$ of the contralateral hand, while the mean extension was found to be $57^{\circ}$ compared to $66^{\circ}$ of the contralateral side.

Conclusions: The evaluated novel technique with the use of PL tendon as interposition material seems to offer satisfying results, while allowing to keep the FCR tendon intact. More studies comparing these techniques are of utmost importance to conclude which is the optimal treatment.
\end{abstract}

Keywords: : interposition arthroplasty, tendon autograft, scaphotrapeziotrapezoidal arthritis, flexor carpi radialis, palmaris longus.

\footnotetext{
Address for correspondence:

Christos Koutserimpas, $M D$

Department of Orthopaedics and Traumatology

"251" Hellenic Air Force General Hospital of Athens, Greece

Kanellopoulou Avenue, Athens, 11525

Tel: 00306948712130

Email:chrisku91@hotmail.com
} 


\section{INTRODUCTION}

solated scaphotrapezotrapezoid (STT) joint osteoarthritis (OA) was firstly reported by Carstam et al in 1968, and its incidence ranges from 2 to $16 \%(1,2)$. It is more frequent among postmenopausal females, while it is often related to first carpometacarpal (CMC) OA, scapholunate dislocation or prior traumatic events $(2,3)$. Furthermore, correlation between flexor carpi radialis (FCR) tendinopathy and STT joint arthritis has also been observed, due to the anatomical and functional relationship between the FCR tendon and the volar surfaces of scaphoid and trapezium bones $(4,5)$.

Numerous treatment methods for isolated STT joint OA have been reported. Non-operative therapy, including activity modification, rest, splints, physiotherapy, anti-inflammatory drugs and corticosteroid injections, is recommended as initial management (6). Surgical treatment should be considered in persistent cases or when conservative treatment fails. Arthrodesis, first described by Watson and Hempton (7), remains the traditional operative management for STT OA,. Other surgical options include distal scaphoid excision, trapeziectomy with or without trapezoidal excision, interposition arthroplasty, and arthroscopic surgery $(6,8)$.

This study aims to report an innovative surgical technique of excisional arthroplasty with the use of palmaris longus (PL) tendon as interposition material, instead of FCR tendon or polycarbon implants, in patients suffering from symptomatic isolated STT OA and to present the outcomes from a small case series.

\section{METHODS}

T he present research is a retrospective observational study. All patients suffering from symptomatic isolated STT OA, without midcarpal instability, and treated with excisional arthroplasty with the use of PL tendon as interposition material, at the Department of Upper limb Hand surgery and Microsurgery of "KAT" General Hospital of Athens, Greece, were evaluated.

Details of symptomatology, clinical examination and imaging findings are presented. The postoperative outcome was evaluated by the abbreviated Disabilities of the Arm, Shoulder and Hand (QuickDASH) score, visual analog scale
(VAS) score for pain and wrist range of motion (ROM).

Informed consent has been obtained from all enrolled patients and the study was approved by the hospital's bioethics committee.

\section{Surgical technique}

Patients were placed supine, while the suffering upper limb rested in supine position on the arm table. Surgical operation was performed under axillary block with a high humerus tourniquet.

The STT joint was reached through a $5 \mathrm{~mm}$ palmar lateral skin incision, while the sensory branch of the radial nerve and the radial artery were protected. At that point, a transverse capsulotomy distal to the scaphoid tubercle was performed to approach the STT joint. Following identification of bony structures, the distal articular surface of scaphoid was osteotomized and removed. Then, the PL tendon was rolled-up like an anchovy and was placed in the remaining space to fill the gap between the scaphoid and trapezium. The capsular and subcutaneous flaps were carefully closed with non-absorbable sutures and the skin was sutured (Figure 1).

Postoperatively, the wrist was immobilized in a short arm dorsal splint in neutral position for four weeks, followed by a rehabilitation program including active and passive wrist flexion, exten-

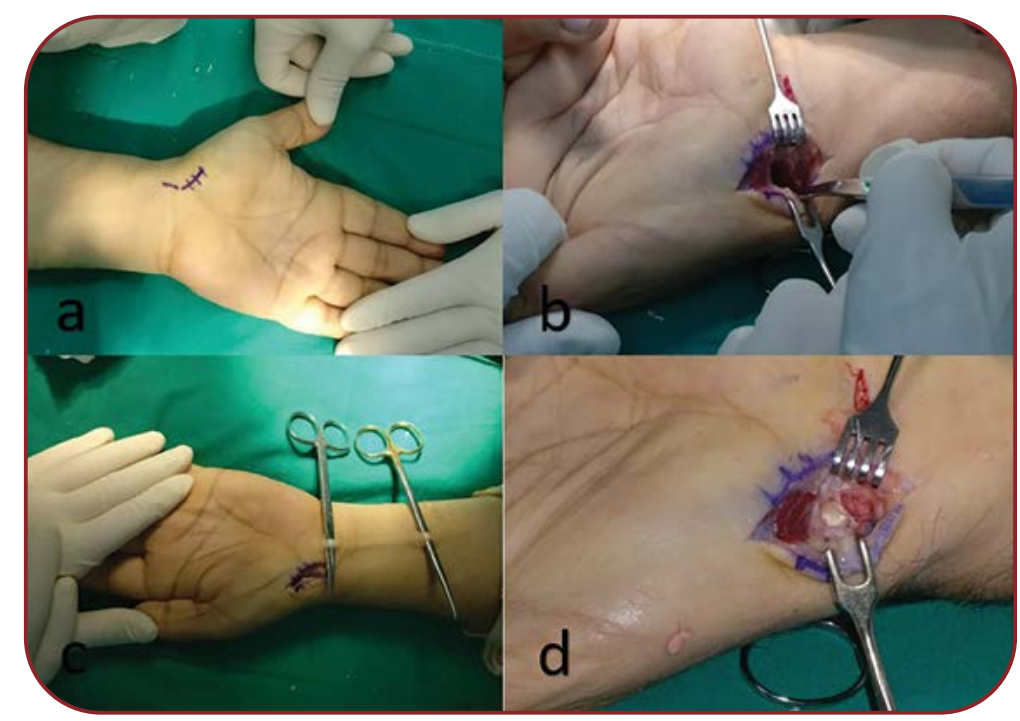

FIGURE 1. Surgical steps: a) drawing of the palmar lateral skin incision, distal to the scaphoid tubercle; b) osteotomized distal articular surface of scaphoid; c) skin incisions over PL tendon autograft; and d) the PL tendon rolled-up like an anchovy and placed in the remaining space 
sion and progressive strengthening with progressive return to daily activities.

\section{RESULTS}

- ive patients (two men and three women) with a mean age of 63.8 years [standard deviation $(S D)=16.9$ ] were included in the present study. The right side was involved in four patients, the dominant side in three cases, while the remaining two subjects were heavy manual laborers. Two patients had suffered from recurrent FCR tendonitis and none of all selected patients had concomitant CMC arthritis. The mean follow up was 56.4 months $(\mathrm{SD}=9.8)$.

The preoperative mean VAS score was 5.8 $(\mathrm{SD}=1.9)$ at rest and $8(\mathrm{SD}=3.5)$ during heavy activity, while the final follow-up mean VAS score was $0.8(\mathrm{SD}=0.8)$ at rest and $3(\mathrm{SD}=2.4)$ during heavy activity, showing a decrease of $86.2 \%$ and $62.5 \%$, respectively.

At final follow up, all patients had continued previous working habits without any restrictions. Two patients reported postoperative minimal discomfort at the extremes of motion or when carrying out very demanding activities. The mean QuickDASH score was found to be 19.54 $(\mathrm{SD}=10.97)$.

Regarding postoperative ROM at final follow-up, patients had a mean wrist flexion of $71^{\circ}$ compared to $78^{\circ}$ of the contralateral hand, while the mean extension was found to be $57^{\circ} \mathrm{com}$ pared to $66^{\circ}$ of the contralateral side.

\section{DISCUSSION}

Caphotrapeziotrapezoidal joint arthrodesis represents the "gold standard" treatment of STT OA. Nevertheless, it has been associated with a significant number of complications such as non-union and progressive radiocarpal joint arthritis $(6,9,10)$. It has been suggested that STT joint arthrodesis altered the kinematics of wrist motion, leading to late secondary changes (11). In 2003, Watson et al presented the results from 800 STT fusions over a 27-year period; the overall complication rate was $13.5 \%$, with $4 \%$ presenting with nonunion, $3.6 \%$ with reflex sympathetic dystrophy, $0.9 \%$ with radial nerve neuromas and $0.8 \%$ with infection (9). Furthermore, STT fusion has also been associated with radioscaphoid impingement in up to $33 \%$ of cases $(9,12)$.

During the last decades, excisional arthroplasty was introduced as an alternative to STT joint fusion in cases without midcarpal instability, since when distal scaphoid was resected in conjunction with inadequate dorsal midcarpal capsuloligamentous elements, the carpus may collapse in a severe DISI deformity with the dorsal subluxation of capitate $(13,14)$. Interposition arthroplasty has proven to be less technically demanding, to require shorter period of immobilization and to have fewer complications when compared to STT joint arthrodesis (13). Table 1 highlights the clinical studies evaluating excisional arthroplasty $(6,11,13,15-18)$.

The present study has revealed satisfactory results regarding ache and function in patients suffering from isolated STT OA, without midcarpal instability, who underwent excisional arthroplasty with PL tendon as interposition material, with a mean follow-up period of 4.7 years. This study represents the first meticulous description of excisional arthroplasty with PL tendon as interposition material and just the second series, with only six patients being previously reported (6).

Through palmar approach following resection of distal scaphoid pole, PL tendon as interposition material was applied. No postoperative complications were recorded during the mean follow-up period of 4.7 years. The use of PL tendon is based on the fact that STT arthritis has been connected with FCR tendinopathy and FCR spontaneous ruptures $(5,6)$. Furthermore, $\mathrm{PL}$ tendon has been widely used as graft in reconstructive surgery, without serious complications (19). Parellada et al suggested that the close anatomical association between the FCR and the subjacent triscaphe joint predisposes the FCR tendon to be involved in arthritic processes, leading to a spectrum of tendinopathy that ranges from tenosynovitis to partial or even complete tear (20). Flexor carpi radialis represents one of the main wrist flexors and also assists in radial deviation of the wrist and pronation of the forearm. The described method with the use of PL tendon has the advantage of avoiding the reduction of wrist flexion which has been recorded when FCR tendon is used.

Apart from tendon autografts, some other interposition materials have been utilized too, with 
TABLE 1. Summary of the studies evaluating excisional arthroplasty for the treatment of scaphotrapeziotrapezoidal arthritis

\begin{tabular}{|c|c|c|c|c|c|c|}
\hline Study & Study design & Population & $\begin{array}{l}\text { Interposition } \\
\text { material }\end{array}$ & Follow up & Outcome and complications & Conclusions \\
\hline $\begin{array}{l}\text { Crosby et al, } \\
1978 \text { (11) }\end{array}$ & $\begin{array}{l}\text { Retrospective } \\
\text { case series }\end{array}$ & 10 wrists & $\begin{array}{l}\text { - four with } \\
\text { FCR } \\
\text { - six with } \\
\text { silicone } \\
\text { implant }\end{array}$ & $\begin{array}{l}37.5 \\
\text { months }\end{array}$ & $\begin{array}{l}\text { - Good results for one silicone } \\
\text { implant and four fibrous } \\
\text { arthroplasties } \\
\text { - Fair results for four silicone } \\
\text { implants } \\
\text { - Poor results for one silicone } \\
\text { implant (implant dislocation) }\end{array}$ & $\begin{array}{l}\text { - Fibrous } \\
\text { arthroplasty with } \\
\text { FCR is a pleasing } \\
\text { technique } \\
\text { - Silicone implants } \\
\text { satisfying but seem } \\
\text { to inhibit further } \\
\text { intercarpal collapse }\end{array}$ \\
\hline $\begin{array}{l}\text { Garcia-Elias } \\
\text { et al, } \\
1999 \text { (15) }\end{array}$ & $\begin{array}{l}\text { Retrospective } \\
\text { case series }\end{array}$ & 21 patients & $\begin{array}{l}\text { - nine with } \\
\text { capsular flap } \\
\text { - three with } \\
\text { FCR } \\
\text { - nine with } \\
\text { no fibrous } \\
\text { interposition }\end{array}$ & 29 months & $\begin{array}{l}\text { - } 13 \text { pain-free wrists, } \\
\text { eight occasional mild } \\
\text { discomfort } \\
\text { - Mean wrist } \\
\text { flexion-extension } 119^{\circ} \\
\text { - Grip and pinch strength } \\
\text { improved } \\
-12 \text { patients with } \\
\text { postoperative DISI }\end{array}$ & $\begin{array}{l}\text { Good pain relief, } \\
\text { more flexion - } \\
\text { extension for wrists } \\
\text { without fibrous } \\
\text { interposition }\end{array}$ \\
\hline $\begin{array}{l}\text { Pequignot } \\
\text { et al, 2005 } \\
\text { (16) }\end{array}$ & $\begin{array}{l}\text { Retrospective } \\
\text { case series }\end{array}$ & $\begin{array}{l}12 \text { patients, } \\
15 \text { wrists }\end{array}$ & $\begin{array}{l}\text { Pyrocarbon } \\
\text { implant }\end{array}$ & Four years & $\begin{array}{l}\downarrow \text { pain } \\
\text { - Slight loss of radial deviation } \\
\text { and wrist extension } \\
\text { - Grip strength similar to } \\
\text { normal side } \\
\text { - Slight } \downarrow \text { in pinch strength }\end{array}$ & $\begin{array}{l}\text { - Good results } \\
\text { - Simple surgical } \\
\text { procedure } \\
\text { - Possible to revise }\end{array}$ \\
\hline $\begin{array}{l}\text { Pegoli et al, } \\
2006 \text { (17) }\end{array}$ & $\begin{array}{l}\text { Prospective } \\
\text { case series }\end{array}$ & Six patients & $\begin{array}{l}\text { Pyrocarbon } \\
\text { implant }\end{array}$ & 19 months & $\begin{array}{l}\text { - DASH score reduced by } 10 \\
\text { - All patients had functional } \\
\text { improvement and returned to } \\
\text { daily activities in three months } \\
20 \% \text { dislocated prostheses }\end{array}$ & $\begin{array}{l}\text { Useful compromise } \\
\text { treatment for this } \\
\text { problem }\end{array}$ \\
\hline $\begin{array}{l}\text { Low and } \\
\text { Edmunds, } \\
2007 \text { (18) }\end{array}$ & $\begin{array}{l}\text { Retrospective } \\
\text { case series }\end{array}$ & $\begin{array}{l}\text { Nine } \\
\text { patients }\end{array}$ & $\begin{array}{l}\text { Pyrocarbon } \\
\text { implant }\end{array}$ & $\begin{array}{l}16.4 \\
\text { months }\end{array}$ & $\begin{array}{l}\text { - Mean DASH score of } 21 \\
\downarrow \text { VAS pain scores } \\
\text { - Mean wrist flexion } 126^{\circ} \text { and } \\
\text { radioulnar deviation } 43^{\circ} \\
\text { - Mean grip strength } 82^{\circ} \% \text { and } \\
\text { pinch strength } 85^{\circ} \% \text { of other } \\
\text { side }\end{array}$ & $\begin{array}{l}\text { Good alternative to } \\
\text { STT fusion }\end{array}$ \\
\hline $\begin{array}{l}\text { Garcia-Elias, } \\
2011 \text { (13) }\end{array}$ & Case report & One patient & Capsulodesis & 28 months & $\begin{array}{l}\text { - Only minimal discomfort at } \\
\text { the extreme of motion } \\
\text { - Wrist extension } 35^{\circ} \text { less than } \\
\text { other side } \\
\text { - Grip and pinch strength } \downarrow \\
15 \% \text { and } 35 \% \\
\text { - Slight DISI malrotation }\end{array}$ & Effective treatment \\
\hline $\begin{array}{l}\text { Berkhout } \\
\text { et al, } \\
2017 \text { (6) }\end{array}$ & $\begin{array}{l}\text { Retrospective } \\
\text { case series }\end{array}$ & $\begin{array}{l}13 \text { patients, } \\
15 \text { wrists }\end{array}$ & $\begin{array}{l}\text { - six cases } \\
\text { with PL } \\
\text { - one case } \\
\text { with APL } \\
\text { - one case } \\
\text { with FCR } \\
\text { - six cases } \\
\text { with no } \\
\text { interposition } \\
\text { implant }\end{array}$ & 4.1 years & $\begin{array}{l}\text { - Normal range on objective } \\
\text { functional outcome and } \\
\text { Q-DASH score } \\
\text { - Mild post-operative DISI } \\
\text { deformity which did not } \\
\text { correlate with pain scores }\end{array}$ & $\begin{array}{l}\text { Satisfactory } \\
\text { midterm results }\end{array}$ \\
\hline
\end{tabular}

reported complications such as silicone synovitis and dislocation of pyrocarbon implants $(6,8,18)$. Also, arthroscopic debridement has been proposed as a treatment option, since it may provide symptomatic relief. Nevertheless, it seems that it does not change the natural progression of STT OA (8).

The present study has some limitations: it used only a relatively small sample, it was performed in a single center and did not encompass a control group. Nevertheless, it represents the first meticulous description of excisional arthro- plasty with PL tendon as interposition material in patients suffering from isolated STT OA. Additionally, it provides just the second series of patients treated with this method and has an adequate follow-up.

\section{CONCLUSIONS}

n conclusion, the technique described here seems to be technically simple and effective for patients suffering from isolated STT OA without midcarpal instability. The present study has re- 
vealed favorable outcomes in a relatively small series of patients undergoing this procedure with a mean 4.7 years follow-up. More research is needed, especially through studies with control groups, comparing excisional arthroplasty with $\mathrm{PL}$ tendon as interposition material to excisional arthroplasty with FCR tendon and to standard STT arthrodesis with relative long follow-up.
Conflicts of interest: none declared.

Financial support: none declared.

Authors' contributions: $K R, C K, A B$ were

responsible for the literature search and analysis

as well as manuscript writing, and EF, SS for the final manuscript revision. All authors have read and approved the final manuscript..

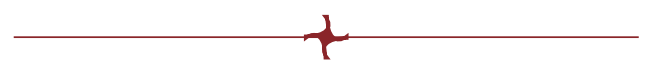

\section{R EFERENCES}

1. Carstam N, Eiken O, Andrén L. Osteoarthritis of the trapezio-scaphoid joint. Acta Orthop. Scand 1968;39:354-358.

2. Viegas SF, Patterson RM, Hokanson JA, Davis J. Wrist anatomy: Incidence, distribution, and correlation of anatomic variations, tears, and arthrosis. J Hand Surg Am 1993;18:463-475.

3. Armstrong AL, Hunter JB, Davis TR. The prevalence of degenerative arthritis of the base of the thumb in post-menopausal women. J Hand Surg Br1994;19:340-341.

4. Allred DW, Rayan GM. Flexor carpi radialis tendon rupture following chronic wrist osteoarthritis: a case report. J Okla State Med Assoc 2003;96:211-212.

5. Tonkin MA, Stern HS. Spontaneous rupture of the flexor carpi radialis tendon.

J Hand Surg Br 1991;16:72-744.

6. Berkhout MJ, Bachour Y, Wessing D, Ritt MJPF. Distal Pole Resection of the Scaphoid for the Treatment of Scaphotrapeziotrapezoid Osteoarthritis. Hand (N Y) 2019;14:230-235.

7. Watson HK, Hempton RF. Limited wrist arthrodeses. I. The triscaphoid joint. J Hand Surg Am 1980;5:320-327.

8. Mathoulin C, Darin F. Arthroscopic treatment of scaphotrapeziotrapezoid osteoarthritis.

Hand Clin 2011;27:319-322.

9. Watson HK, Wollstein R, Joseph E, et al. Scaphotrapeziotrapezoid arthrodesis: a follow-up study. J Hand Surg Am 2003;28:397-404.

10. Spekreijse KR, Selles RW, Kedilioglu MA, et al.

Trapeziometacarpal Arthrodesis or Trapeziectomy with Ligament Reconstruction in Primary Trapeziometacarpal Osteoarthritis: A 5-Year Follow-Up. J Hand Surg Am 2016;41:910-916.

11. Crosby EB, Linscheid RL, Dobyns JH. Scaphotrapezial trapezoidal arthrosis. J Hand Surg Am 1978;3:223-234.

12. Rogers WD, Watson HK. Radial styloid impingement after triscaphe arthrodesis. J Hand Surg Am1989;14:297-301.

13. Garcia-Elias M. Excisional arthroplasty for scaphotrapeziotrapezoidal osteoarthritis.

J Hand Surg Am 2011;36:516-520.

14. Tay SC, Moran SL, Shin AY, Linscheid RL. The Clinical Implications of Scaphotrapezium-Trapezoidal Arthritis With Associated Carpal Instability.

J Hand Surg Am 2007;32:47-54.
15. Garcia-Elias M, Lluch AL, Farreres A, et al. Resection of the distal scaphoid for scaphotrapeziotrapezoid osteoarthritis. J Hand Surg Br 1999;24:448-452.

16. Pequignot JP, D'asnieres de Veigy $L$, Allieu Y. [Arthroplasty for scaphotrapeziotrapezoidal arthrosis using a pyrolytic carbon implant. Preliminary results]. Chir Main 2005;24:148-152.

17. Pegoli L, Zorli IP, Pivato G, et al. Scaphotrapeziotrapezoid joint arthritis: a pilot study of treatment with the scaphoid trapezium pyrocarbon implant. J Hand Surg Am 2006;31:569-573.

18. Low AK, Edmunds IA. Isolated Scaphotrapeziotrapezoid Osteoarthritis: Preliminary Results of Treatment Using a Pyrocarbon Implant. Hand Surg 2007;12:73-77.

19. Georgiev GP, Iliev AA, Dimitrova IN, et al. Palmaris Longus Muscle Variations: Clinical Significance and Proposal of New Classifications.

Folia Med (Plovdiv) 2017;59:289-297.

20. Parellada AJ, Morrison WB, Reiter SB, et al. Flexor carpi radialis tendinopathy: spectrum of imaging findings and association with triscaphe arthritis. Skeletal Radiol 2006;35:572-578. 